\title{
ENGAGING STUDENTS THROUGH WRITING: A COLLABORATIVE JOURNEY
}

\author{
L. M. Drennan \\ Unit for Language Development \\ University of the Free State \\ Bloemfontein, South Africa \\ e-mail: drennanl@ufs.ac.za
}

\section{ABSTRACT}

Access to and success in South African higher education present several challenges, particularly on an academic literacy front. Yet, higher education institutions are expected to ensure that students make a success of their studies. A plausible response to this challenge is to change the approach to academic literacy and writing within the disciplines. The article discusses how the current practices at the writing centre of the University of the Free State aim to address students' subject-specific writing needs in collaboration with disciplinary academics. The data from two collaborative initiatives demonstrates positive perceptions of the writing interventions, as well as a possible impact on students' writing performance. There is, however, a need to investigate, by means of further detailed case studies, the impact of a more collaborative writing-intensive approach to writing on student performance within the disciplines.

Key words: academic literacy, academic writing, writing centre, student writing development, collaborative partnerships

\section{INTRODUCTION}

The social and political imperative ( $c f$ the DHET's latest White Paper on Post-School Education and Training 2014) to widen access to higher education in South Africa presents several challenges, particularly with regard to the envisaged success of students enrolled in higher education institutions. As a result of widened access, higher education institutions are required to address issues pertaining to academic literacy, students' language needs, teaching and learning practices within institutions, the types of assessment in courses, student motivation and engagement, to name but a few (Hutchings 2006, 247). Many of these issues are due to learners emerging from a schooling system that has not provided them with adequate exposure to the learning experiences necessary to develop the concepts and schemas necessary to deal with tertiary studies (Thesen and Van Pletzen 2006).

In the face of these challenges, higher education institutions remain responsible for ensuring that students achieve course and content goals and make a success of their studies. However, the prerequisite is that students have adequate literacy skills. Literacy refers to 
'mastery or fluent control over a secondary discourse' (Gee 1990,143) and discourse to socially accepted ways of using language and of being so that one can 'identify oneself as a member of a socially meaningful group or "social network”" (Boughey 2002, 296). In order to be effective in assisting students to achieve success in their studies they need to be engaged in learning activities that encourage and develop critical thinking, reading and writing. These are all literacy acts that need to be learned and practised in the subject areas (Clarence 2012); they are discipline-specific, as each discipline has a unique way of making meaning and constructing knowledge according to the conventions of that particular field of study (Lillis 2001).

It is often assumed that academic writing is a generic skill whose conventions can be taught in a decontextualised setting and simply transferred to the various subject areas (Archer 2010). This is not the case. Academic writing, as mentioned earlier, is a literacy act that has to be learned and practised within the context of a particular discipline. Clarence $(2012,127)$ claims that it is a 'social and knowledge practice that is informed by the values and academic conversations of particular disciplines and the ways in which knowledge is constructed and disseminated by these disciplines'. However, what is considered 'conventional' in terms of academic writing also poses problems. Although content lecturers and tutors are aware of what is expected in writing in their particular discipline, they struggle to pinpoint and convey their understanding of disciplinary conventions and expectations to students (Lillis and Turner 2001; Clarence 2012). Lillis and Turner $(2001,58)$ point out that lecturers and tutors can tell students that they are required to include clear introductions in their academic essays, but they do not tell students what goes into an introduction and in what order certain information should be presented. They also tell students to cite sources and not to plagiarise, but they take for granted that students know when to refer to certain sources, how to integrate information, when and how to use in-text references, and that students possess the subject-specific vocabulary to 'write information down in their own words' so as to avoid plagiarising. Students are also expected to write assignments free of flawed punctuation and incorrect grammar, but they are not shown where the language errors are in their texts and how to go about correcting these errors. In addition, students need to be able to formulate arguments and structure their assignments according the specifications of various genres, yet being able to develop an argument requires the student to be familiar with the conventions of paragraph writing in terms of opening statements (topic sentences) and supporting sentences and their respective functions; synthesis and integration of information from external sources; cohesion and coherence, and the function and use of various discourse markers necessary to achieve the required flow in academic writing. It is also assumed that students possess an understanding of audience and purpose, 
which they do not have if they have not been made explicitly aware of how the nature of the assignment influences these concepts.

One plausible way to address student engagement and expose students to the writing conventions of their disciplines is by changing the way academic writing and literacy are imparted in the disciplines. If students are to improve their critical thinking, reading and writing skills, then opportunities to do so need to be provided for in the various subject areas. A writingintensive approach to teaching and learning stimulates critical thinking, particularly when students need to write about significant problems in their subject field (Bean 2011). Bean (2011, xiii) furthermore emphasises the link between thinking and writing, as when students struggle with their writing they are required to grapple with their thinking as well. Writing also provides a space where students can explore their ideas and the ideas of others, and where these ideas can be brought together to help students make sense of the various concepts and experiences being explored (Burke 2008, 199). As Archer $(2008,210)$ points out, writing 'is of the main means of assessment in tertiary institutions'. However, how writing assignments are designed, how they are assessed, and how often students are required to write, is of critical importance. This is where the writing centre can help both academic staff members and students. The writing centre serves as an intermediary between students and lecturing academics. By means of collaborative partnerships between writing centre practitioners and disciplinary academics, writing assignments can be carefully designed and scaffolded to meet the developmental needs of students (Bean 2001; Clarence 2012; Dannels and Gaffney 2009) so as to facilitate students’ success in higher education studies.

This article looks at the current practices of the University of the Free State (UFS) writing centre and how they are geared towards fostering collaborative partnerships with academic lecturers in the disciplines with regard to addressing students' literacy, in particular their writing skills. The following section briefly discusses the role of the writing centre within the context of South African higher education, as well as an outline of the approach taken. Thereafter, the details of exemplary collaborative partnerships between the writing centre and disciplinary academics are provided. Lessons learned and experiences from these collaborative initiatives are then discussed, followed by reflections and recommendations.

\section{THE ROLE OF THE WRITING CENTRE}

The writing centre was initiated as part of the academic literacy work done by the Unit for Academic Literacy (UAL) at the UFS. The aim was to address academic staff members' complaints about students' inability to write according to the academic conventions of the 
institution. In accordance with the approach taken to academic literacy by the UAL, an 'academic literacies' stance was assumed in the work done in the writing centre, where writing is viewed as a 'social practice, and part of a contested space; where the writing itself is part of negotiating and constituting that space' (Clarence 2012, 128). Burke (2008) also argues that one cannot teach writing outside of the specific context in which teaching and writing occur. The teaching of writing needs to be positioned in the discipline, as writing is what individuals 'do’ as situated actors in a particular discourse community (Archer 2008; Lea and Street 2006).

The UFS writing centre currently aims at establishing collaborative relationships with content lecturers across disciplines. Content-area lecturers approach the writing centre in connection with individual assignments due in their subject area. A course of action is negotiated regarding the development and presentation of tailor-made workshop materials around the particular writing needs of students and the type of assignment due. The lecturers communicate the details of the assignment and the problems their students generally encounter in their writing. In the main, lecturers have indicated that students struggle with formulating proper introductions and thesis statements; developing and supporting arguments; synthesising and integrating information from sources; formulating proper paragraphs; referencing and avoiding plagiarism; and avoiding grammatical and punctuation errors.

As mentioned earlier in the article, these academic writing conventions cannot be imparted in isolation; they need to be couched in the specific context in which they are taught. For this reason, the writing centre workshop materials incorporate authentic texts and samples of students' writing in a particular discipline. These discipline-specific texts are used as a point of departure to address the specific writing conventions relevant to the assigned writing task. Examples from workshop materials will be presented later on in the article.

Students are divided into small groups, preferably no more than 35 students per group for the various subject areas, and the writing workshops are presented to help prepare students for the assignment due for a particular subject. Thereafter, students avail themselves for the oneon-one consultancy service offered by the writing centre by making use of either the online bookings or walk-in services. Students are required to bring a draft of their assignment to these individual sessions which form the basis of the consultation. Students frequently come only with an outline of their envisaged approach to the assignment and the consultant helps them unpack the topic and discusses the requirements for the assignment. Consultants are instructed to first deal with higher-order issues regarding students' writing, such as organisation and structure, before they move on to lower-order issues, such as punctuation and grammar. A report of the students who visited the writing centre for a particular assignment is generated and 
sent to the content-area lecturer.

As a rule, in accordance with current practice at other South African writing centres (Archer 2008, 212), the aim of the UFS writing centre is to address the following during individual consultations: helping students understand that writing is a process and that they need time to work on several drafts of an assignment before submission; helping academic staff and students understand the concept of 'writing to learn, and learning to write' (Condon and Rutz 2012; Britton 1972) - that writing is a helpful tool to come to grips with difficult content; creating a sense of awareness about audience and practice when writing assignments for different disciplines; helping students develop their authentic voice and avoid plagiarism; showing students how to integrate information from various sources and cite correctly; improving students' sense of flow in academic texts in terms of coherence, cohesion and logic; pointing out the typical writing conventions in specific disciplines; and guiding students' discovery of typical language-related errors in their writing to enable them to self-edit future assignments. The writing centre places much emphasis on its aim to develop better writers, not necessarily produce perfect assignments. It is important to highlight this aspect if the writing centre is to move away from being seen as a remedial centre, a 'dumping ground' for underprepared students, or a 'fix-it shop' where students' work is 'edited'. The writing centre practitioners are hard at work establishing a culture of writing as a process on campus. Given that the UFS writing centre is still in its infancy, such a culture will take time to establish; it will only be possible through buy-in and support from academic lecturers as well as by way of collaborative partnerships.

\section{INTER-DISCIPLINARY COLLABORATION}

The UFS writing centre has collaborated with several academics across a number of disciplines since its commencement in 2012. However, the work with two departments in particular, Law and Medicine, will be used to illustrate the collaborative approach taken to writing across the curriculum.

\section{Law faculty}

\section{Scope of initiative}

The work with the Law faculty was started in 2014 when the Legal Skills lecturer contacted the writing centre regarding students' poor performance on written assignments. Since then the writing centre practitioners have been working closely with the lecturer towards addressing her 
students' academic writing skills. One of the initiatives selected for elaboration in this article is an academic essay that 198 first-year Legal Skills students had to write on 'the importance of a plagiarism policy for a) the UFS, b) the Faculty of Law and c) the student'. The lecturer expressed her expectation that her first-year students should be able to write essays that: made use of simple language and clear expression; were grammatically accurate; were precise and free of ambiguity; adhered to the structure of an academic essay; were responsive in terms of audience, purpose, style and tone. The expectation was that the writing centre would also help students structure their assignments according to the conventions of academic essay writing.

The proposed course of action for these students consisted of two compulsory interventions: a one-hour, face-to-face workshop followed by an individual session at the writing centre. These two interventions were carefully scaffolded so that the concepts addressed in the workshop were further developed in the individual sessions at the writing centre. It was the lecturer's decision to make the interventions compulsory for students. The workshop, which focused on the structure of an academic essay, took place during the scheduled content lecture. The 198 students enrolled for the Legal Skills course were divided into five groups to encourage participation and engagement during the workshop. Thereafter, students attended individual sessions in the week assigned to their respective groups. This was done in an effort to ensure that all the Legal Skills students could be assisted with an individual session. Given that the writing centre services all undergraduate students at the UFS, capacity is a constant challenge and special arrangements need to be made with departments to meet the needs of their students regarding individual sessions.

The one-on-one sessions at the writing centre were geared towards helping students with the first draft of their essays. During this session, writing consultants were instructed to look specifically at higher-order issues first, such as structure and organisation, the development of arguments, integration of information from sources, and paragraph formulation. Lower-order issues, such as grammar, punctuation and referencing were only dealt with if there were very few or no higher-order issues in the first draft. If necessary, students were encouraged to come for follow-up sessions to deal with issues that were not addressed in the first session.

In terms of data, both qualitative and quantitative data was gathered. Students completed an evaluation questionnaire after the workshop comprising a demographic section containing nine single-option, multiple-choice questions, followed by a section made up of five Likertscale questions evaluating student perceptions of the workshop materials. The final section of the questionnaire contained six open-ended questions requesting student commentary regarding the workshop. Students' scores on the Legal Skills essay were also made available by the 
content lecturer.

\section{Approach to materials development}

The workshop materials were geared towards generating awareness about the conventions of academic essay writing with regard to an introduction, 'body' paragraphs and a conclusion. As indicated earlier in the article, although content lecturers are aware of the required format of an academic essay (Lillis and Turner 2001, 58), they do not tell students what constitutes good essay writing, as unpacking the conventions of various discourses is not their field of expertise. For this reason, the writing workshop materials were carefully scaffolded to accommodate the developmental writing needs of the students in question. Firstly, the important components of an introduction were addressed in terms of background information, thesis statement and direction (road map for the rest of the text). Thereafter, paragraph formulation was unpacked with regard to topic sentences and supporting sentences and the use of transitional devices. The final component addressed in the workshop was the function and format of a concluding paragraph. These components of academic essay writing were not de-contextualised; samples from genuine legal texts and students' novel responses regarding the essay topic assigned to them for Legal Skills were used as a means of unpacking and teaching these aspects.

The purpose of the workshop was not to teach students to generate well-formulated introductory, body, and concluding paragraphs, but rather, by means of interactive activities, to make them aware of the conventions of academic essay writing in their field of study. The intention was to get students to use the workshop handouts towards the planning and first drafts of their essays on plagiarism for Legal Skills. Consultants then facilitated the transfer of skills from the workshop during the individual sessions at the writing centre by referring to the workshop handouts when working through students' writing so as to ensure that students understood what was expected in terms of the required essay format. Since students had to justify their proposed arguments to the consultant, the individual sessions were very much about negotating meaning and 'talking' about writing, thereby establishing 'a sense of control in the writer over their learning and texts’ (Hutchings 2006, 250).

\section{Medical faculty}

\section{Scope of initiative}

One of the compulsory courses for medical students involves visits to local clinics in small groups. The course assessment calls for students to write a 1000-word critical reflective essay 
based on their experiences of the clinic visits. The Medical faculty approached the writing centre to assist 128 first-year students with this critical reflective essay writing. The content lecturer requested that the writing centre address students' ability to reflect critically on the impact of these clinic visits on future learning and practice within the field of Medicine.

The course of action for this cohort of students involved one compulsory information session, a compulsory small-group workshop, followed by an optional individual session at the writing centre. Writing centre practitioners addressed the notion of critical reflective journal writing in the information session during one of the students' scheduled content lectures. Thereafter, students attended the small-group workshops in the same groups in which they attended the clinic visits. These group sessions focused on the prescribed format of the critical reflective writing assignment. Thereafter, students could book individual sessions at the writing centre during which consultants ensured that the principles covered in the small-group workshops were applied to students’ critical reflections.

The data collected for the intervention with the medical students was the same as for the Law faculty. Both qualitative data, in the form of questionnaire responses and individual session feedback, and quantitative data, in the form of students' critical reflective essay scores, was gathered.

\section{Approach to materials development}

The group workshop materials were geared towards helping students understand the three components of critical reflection - factual ('what?'), interpretative ('so what?') and application ('now what?'). The materials were carefully scaffolded to help students understand and respond to the various prompts assigned for the critical reflective essay. Firstly, students worked in pairs and discussed what they knew and did not know about the critical reflective format. Thereafter, they were provided with theory pertaining to the structure of reflective writing. The figure below was used to explain the reflective process.

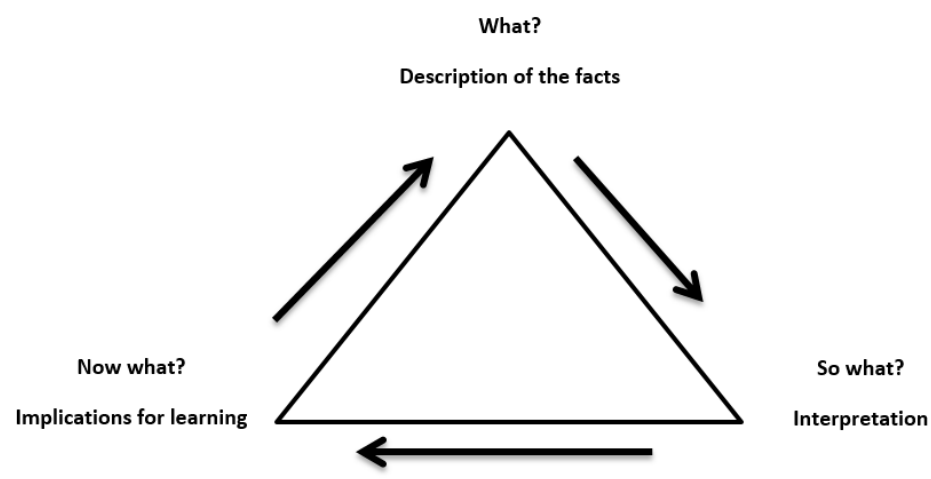

Figure 1: Critical reflective process 
Genuine student samples from previous years' critical reflective essays were used to test students' understanding of the required format. Sample paragraphs were analysed and students had to discuss in groups whether the samples were good or poor examples of critical reflective paragraphs and provide feedback to the class. Thereafter, students had to select one or two of the prescribed prompts and complete a table based on their visits to the clinit, after which they shared their answers in groups. The excerpt below illustrates the latter process.

\section{Activity 6 (Excerpt)}

\subsection{Answer at least two of the following prompts based on your recent clinic visit.}

1. What was special about your clinic visit today?

2. What did the experience remind you of?

3. What did you learn that you did not know before (about yourself, your fellow-students, the people at the clinic, the services that are available)?

6.2 Use the table below to answer the two prompts of your choice.

\begin{tabular}{|l|l|}
\hline Prompt: & \\
\hline What? (Description/facts) & \\
\hline So what? (Interpretation/emotion) & \\
\hline Now what? (Impact/learning) & \\
& \\
\hline
\end{tabular}

The final component of the workshop required that students use the information in the table to generate a critical reflective paragraph for the prompt/s they selected. Sample responses were again used to illustrate the use of linking words and phrases to create flow in writing. Students were provided with a table of transitional words and phrases, as well as the function of each transition (e.g. to add information, to conclude, to show sequence, etc.) to use towards writing their paragraphs. Again, sample paragraphs were selected for analysis and feedback in the plenary. The writing centre practitioners selected sample responses during the workshop and worked through them in the plenary.

\section{DATA ANALYSIS AND DISCUSSION}

The feedback provided by consultants, students and lecturing academics has been key to determining current practice at the UFS writing centre. The quantitative data from the questionnaire, consultant feedback, as well as assignment scores was analysed using Excel. The qualitative data from the questionnaire and consultant feedback was coded according to 
recurring themes and also analysed using Excel. The feedback of the various stakeholders will be reported on briefly in this section, as well as recommendations regarding the approach to future collaborative initiatives.

\section{Law faculty}

Of the 173 students registered for the Legal Skills course, only 118 attended the workshop, even though attendance was compulsory. Those who attended were found to have positive perceptions of the workshop. The majority of students (93\%) indicated that they better understood the writing task after the workshop and 91.5 per cent indicated that they better understood the required structure of the writing task post workshop.

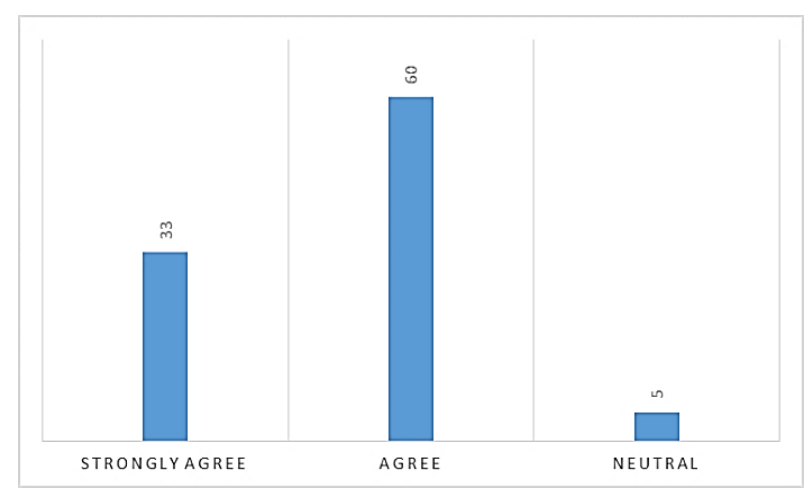

Figure 2: Perceptions regarding understanding of writing task

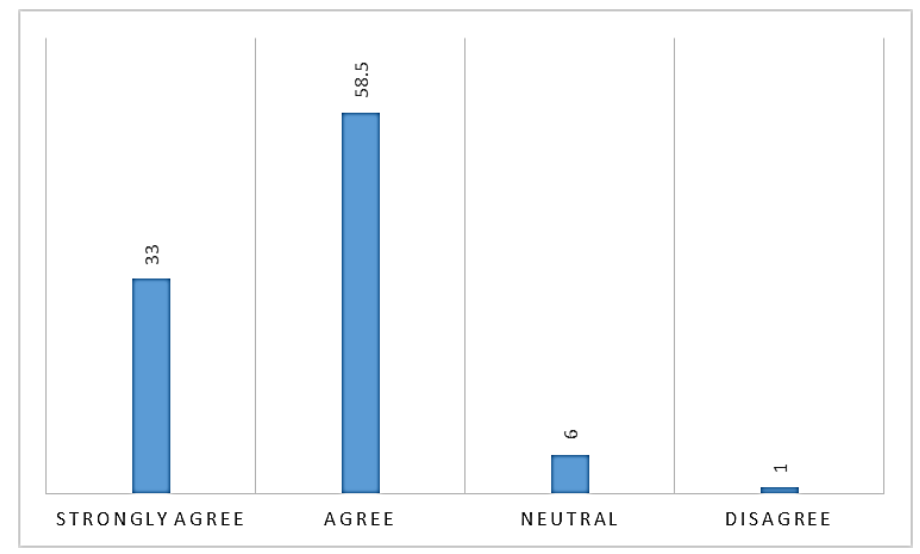

Figure 3: Perceptions regarding understanding of required structure of writing task

In terms of the value of such workshops, 75 per cent of participants said they would not have clearly understood what was expected of them regarding the writing task had it not been for the workshop and 94 per cent of students agreed that such writing workshops are necessary to help students approach writing tasks. 


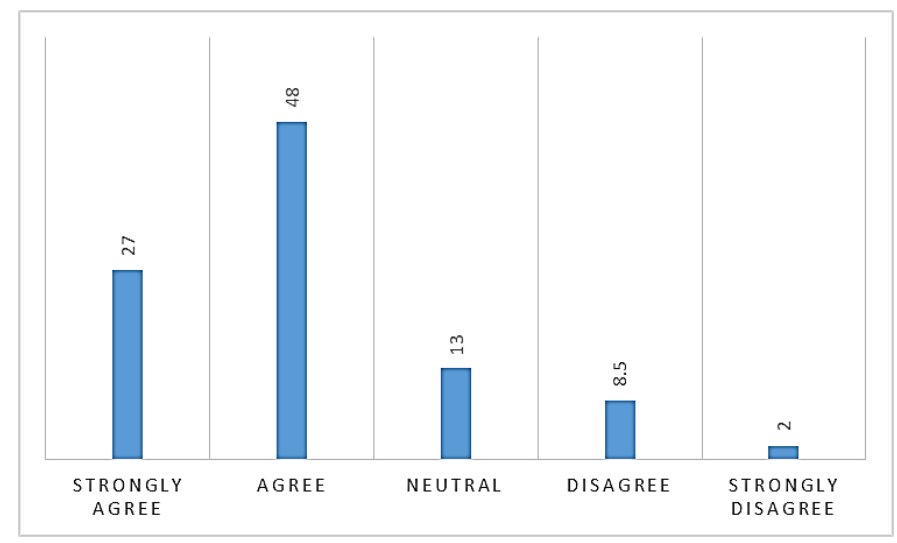

Figure 4: Perceptions of expectations regarding writing task

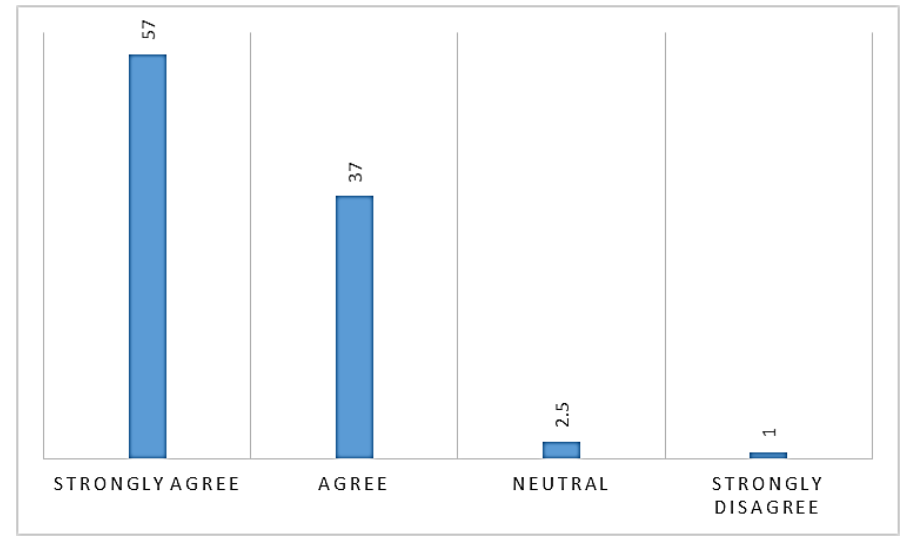

Figure 5: Perceptions regarding necessity of writing workshops

Coding the qualitative data revealed six common themes amongst student responses to the open-ended questions on the questionnaire. When students were asked what they liked most about the workshop, the themes that emerged included presentation, content of the workshop, interaction, environment, understanding of the writing process and impact on skills. The percentages in the figure below illustrate that students generally liked the presentation and content most. Presentation was the theme that occurred most frequently, with students commenting that they liked 'the way in which things were explained' '... in detail' and that they enjoyed 'the presenting skills of the presenter'; that the 'facilitator was friendly and willing to help'. Even though presentation is very important when it comes to teaching and learning, it does not necessarily equate to success in student performance in writing tasks.

Given that the aim of the workshop was to generate awareness of the conventions of academic essay writing and not necessarily influence students’ writing skills, it is not surprising that students did not mention 'impact on skills' frequently. A shortcoming associated with large face-to-face workshops is that it impedes students' engagement and response rate in the plenary (Bailey 1996). Although the 173 students registered for Legal Skills were divided into five 


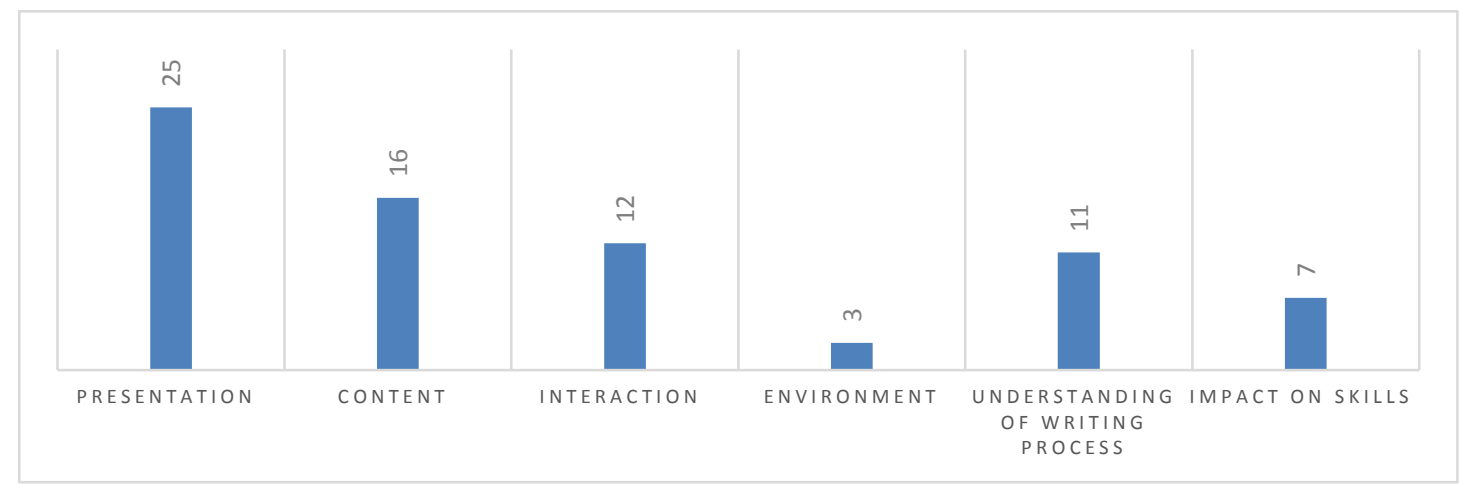

Figure 6: Common themes regarding what students liked most about the workshop

groups in an effort to work with smaller groups, not all students attended in their groups. Instead, two groups had nearly 50 students in the workshop, whereas another group had only 8. The large class size, as well as venues with tiered seating that makes group work and interaction difficult, could possibly account for why students did not mention 'interaction' and 'understanding of the writing process' more frequently. If students' interaction was impeded due to fear of ridicule, anxiety to contribute to the class as a result of low proficiency, as well as teacher and peer intolerance of silences or hesitations (Bailey 1996), this could have adversely affected their understanding of the workshop materials, as 'comprehension is best assisted when the content of the directions [is] repeated and rephrased in interaction' (Pica, Young and Doughty 1987, 737).

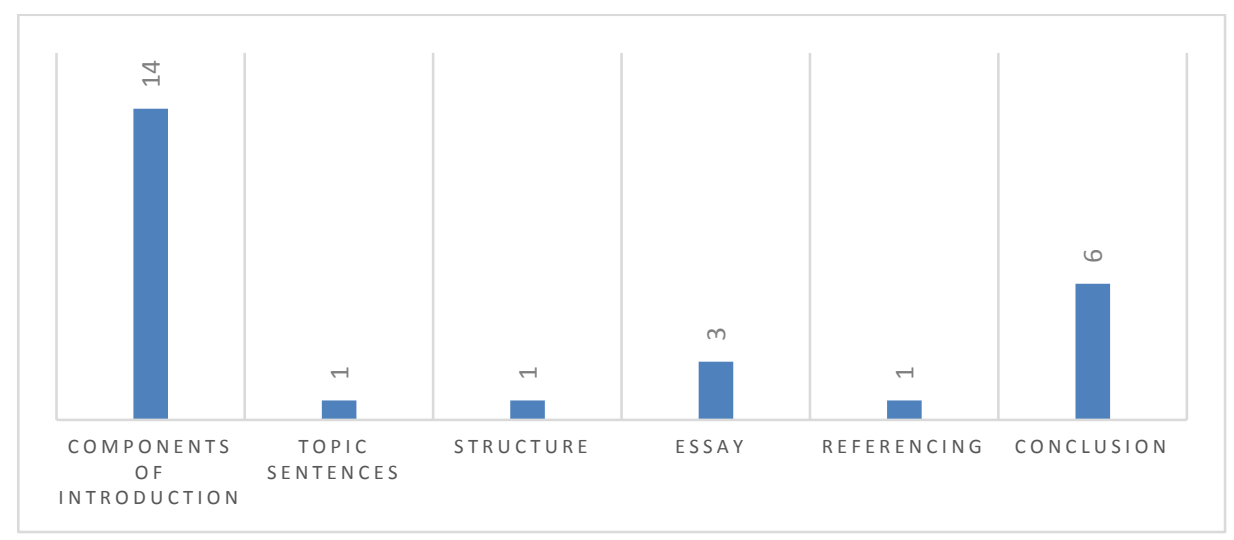

Figure 7: Common aspects that students feel unsure about

Student responses regarding the aspects they still felt unsure about after the workshop alluded most frequently to the components of an introductory paragraph (background information, thesis statement and direction). It is difficult to say whether students mentioned this because they were made aware of the various components of an introduction during the workshop and realised they needed additional assistance in this area, or whether the workshop materials were 
not particularly effective in helping them understand what was expected of them in terms of introductory paragraph writing. However, in language learning, students learn by engaging with the target language and practising the skills that need to be developed (Boughey 2002; Clarence 2012; Archer 2010). This was the purpose of the individual sessions during which students receive help regarding their individual writing needs. Table 1 lists the scope of the various tutorial types employed by writing consultants. Accordingly, the consultant feedback presented in Figure 8 illustrates that the majority of students required help either on an organisational level (42\%), or at paragraph level (61\%), both of which include the format of an introduction.

Table 1: Scope of tutorial types

\begin{tabular}{|l|l|}
\hline Tutorial type & Scope \\
\hline Invention & Free writing, listing, brainstorming, diagramming \\
\hline Assignment & Understanding audience, purpose, subject \\
\hline Organisational & Using outlines to arrange ideas \\
\hline Drafting & $\begin{array}{l}\text { Writing in the writing centre to fit the assignment and test the outline employing } \\
\text { invention techniques }\end{array}$ \\
\hline $\begin{array}{l}\text { Audience } \\
\text { review }\end{array}$ & $\begin{array}{l}\text { Identify the purpose; use language to address audience appropriately; use the level } \\
\text { of information appropriate for audience }\end{array}$ \\
\hline Paragraph & $\begin{array}{l}\text { Discuss topic sentence, purpose, number of paragraphs, length of paragraphs to } \\
\text { achieve proportion, one subject per paragraph }\end{array}$ \\
\hline Sentence & \begin{tabular}{l} 
Syntactical and grammatical errors; incorrect spelling and punctuation \\
\hline
\end{tabular}
\end{tabular}

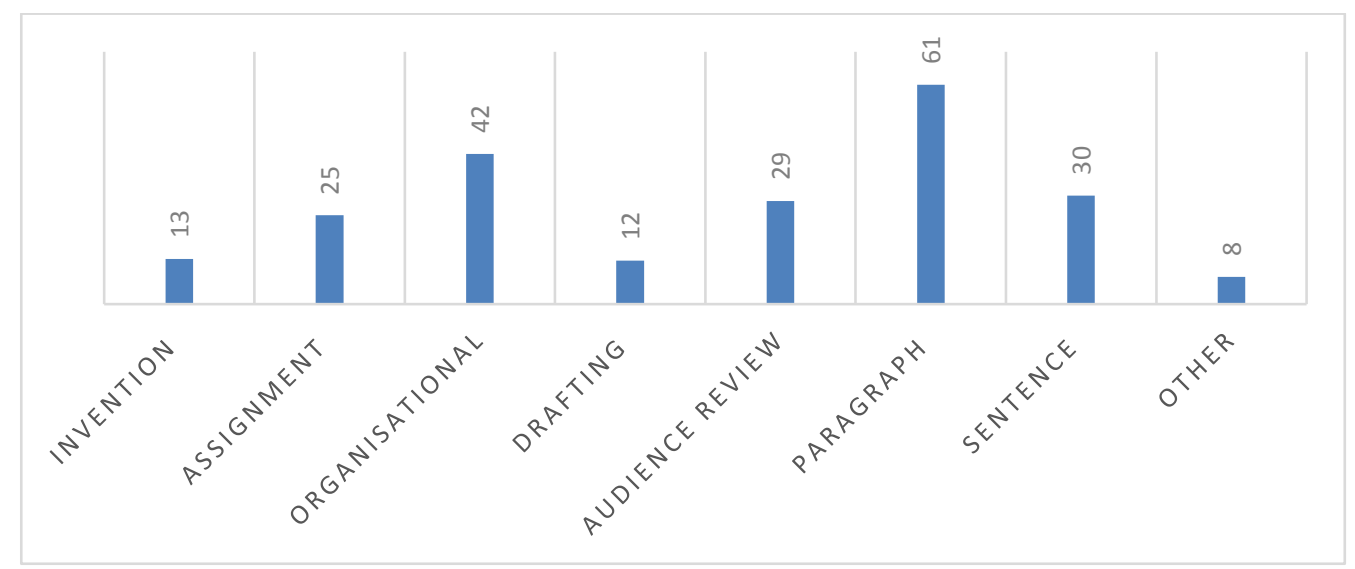

Figure 8: Individual session tutorial frequency

Since the individual sessions built on concepts addressed in the workshop materials, the scores of the students who attended the workshop and/or individual sessions were compared with the scores of those students who chose not to attend either the workshop or individual sessions. The figure below seems to suggest that the students who attended both the workshop and individual sessions performed better than those who only attended the workshop or individual sessions. Also, the students who did not attend either intervention scored on average at least 7 per cent lower than the participants who had some sort of writing intervention. 


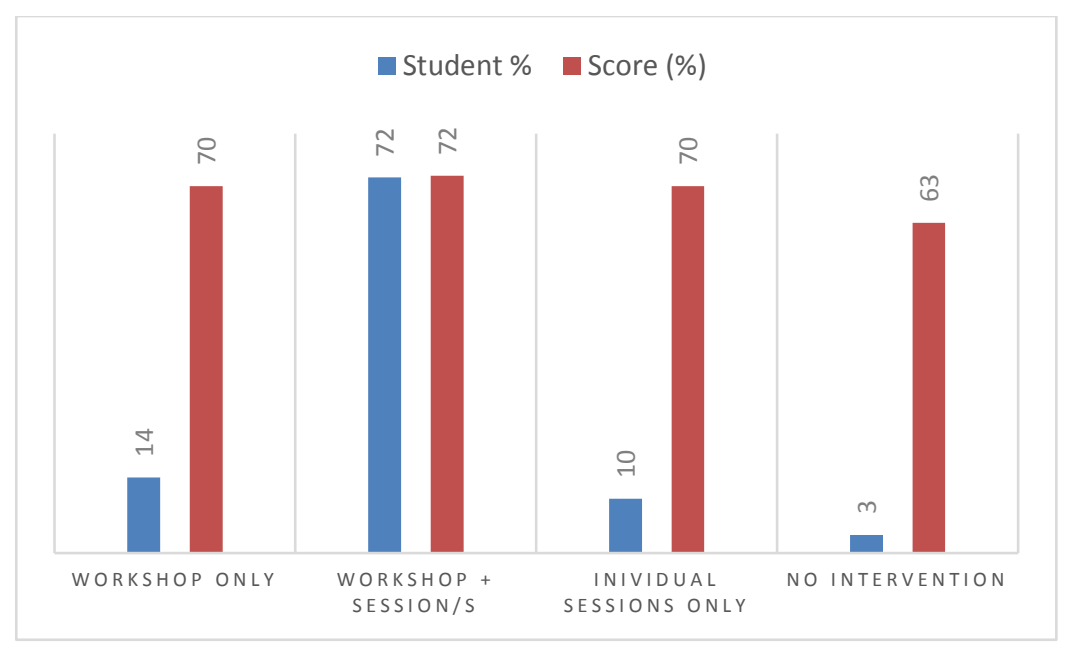

Figure 9: Comparison between intervention attendance and task performance

Although the findings suggest that the intervention was perceived positively and that students generally fared well in their essays, there are various limitations to the study. The sample size of students who did not participate in some sort of intervention (6 out of 173 students) is essentially too small to compare. However, for ethical reasons, one cannot justify having a control group that is denied additional support that could potentially improve their academic performance. Further, it is very difficult to measure the impact of any one given intervention, given the myriad of factors, such as prior learning, level of proficiency, exposure to other academic support initiatives and the like, that could serve as potential mediating factors in students’ academic performance.

\section{Medical faculty}

Although the small-group workshops were compulsory for the 128 registered students on the medical course, only 64 attended. These students, however, perceived the workshops very positively. Almost all the participants (98.4\%) indicated that the workshop helped them better understand the writing task, and 97 per cent said they better understood the required format of the critical reflective essay post workshop.

The majority of students (87.5\%) also stated that they would not have understood as clearly what was expected of them had they not attended the workshop. In addition, almost all the participants (98.4\%) felt that such workshops are necessary to help students approach writing tasks.

The themes that emerged during the coding of the qualitative data were the same as those for the Law cohort. The medical students indicated that they enjoyed the presentation (39\%) and the interaction (34\%) most about the workshops. The degree of interaction in these workshops could account for the higher rate of 'understanding of the writing process', which 


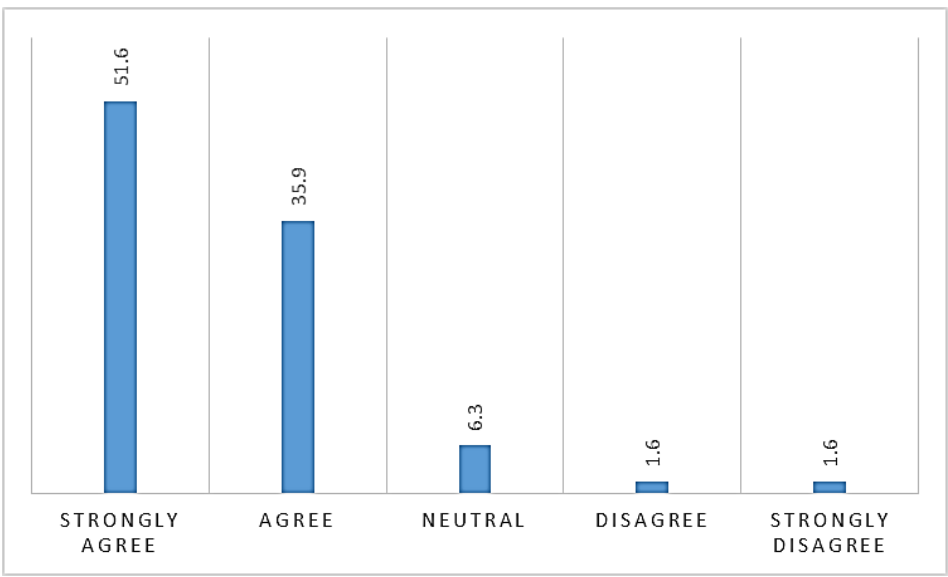

Figure 10: Perceptions of expectations regarding writing task

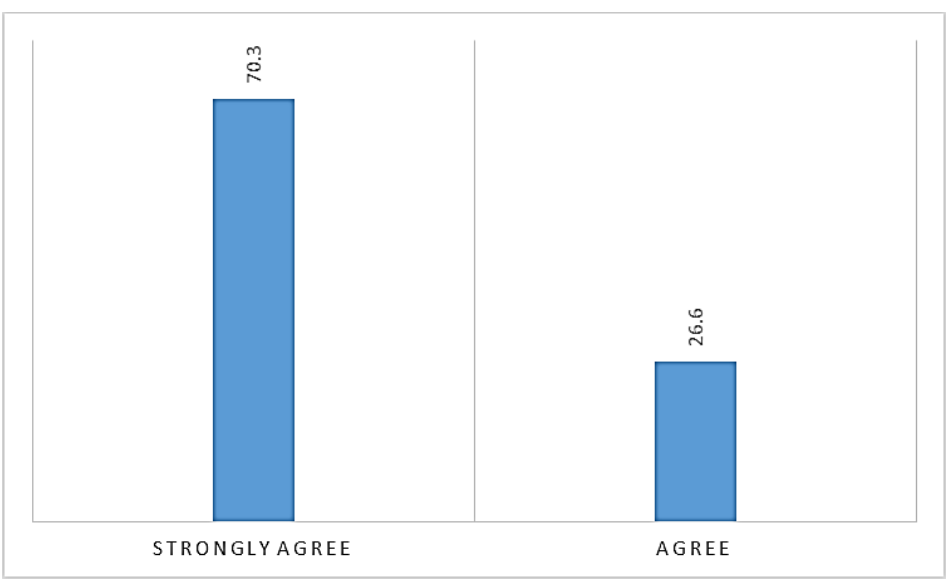

Figure 11: Perceptions regarding necessity of writing workshops

was 17 per cent for this cohort as opposed to 11 per cent for the Law group. This might also be a result of smaller group sizes, as well as the venues in which the workshops took place. The writing centre practitioners booked venues for these small-group interventions with movable chairs and table, which facilitated group discussions, student engagement and interaction.

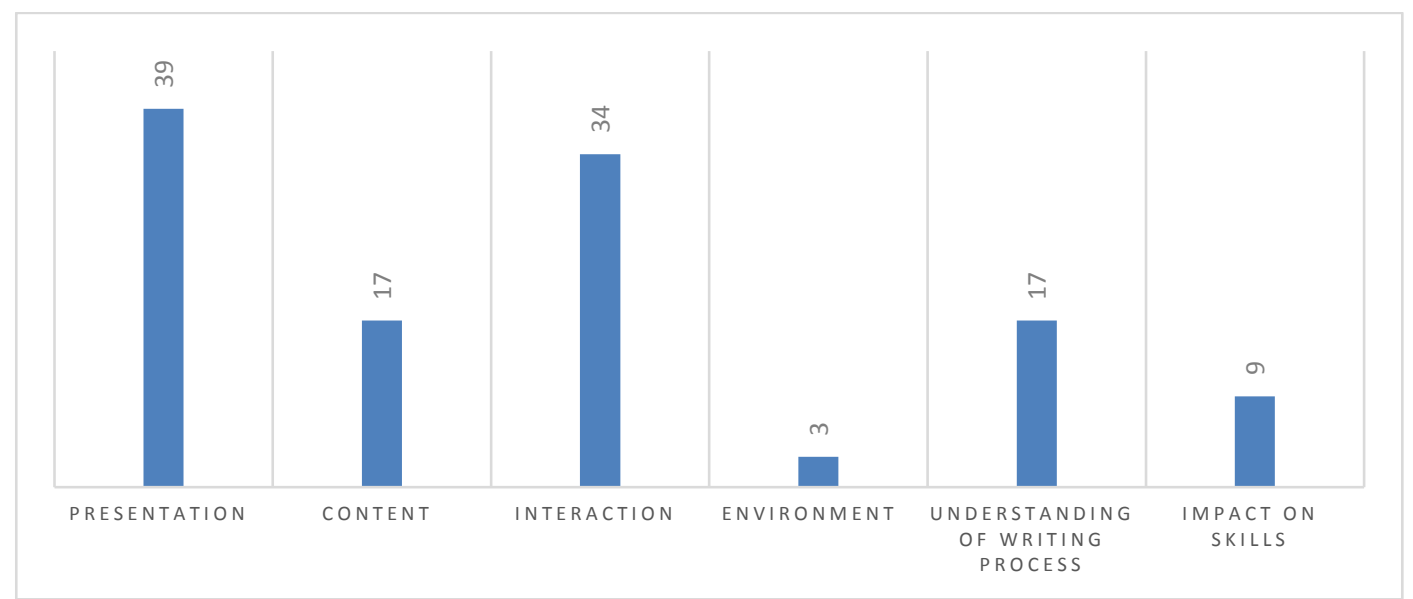

Figure 12: Common themes regarding what students liked most about the workshop 
With regard to the aspects the medical students still felt unsure about after the workshop, a small portion of students (8\%) indicated the concluding paragraph. Only 2 per cent of students mentioned register, coherence and the introduction as areas that required further elaboration. It should be noted that the workshop materials did not cover the concluding paragraph.

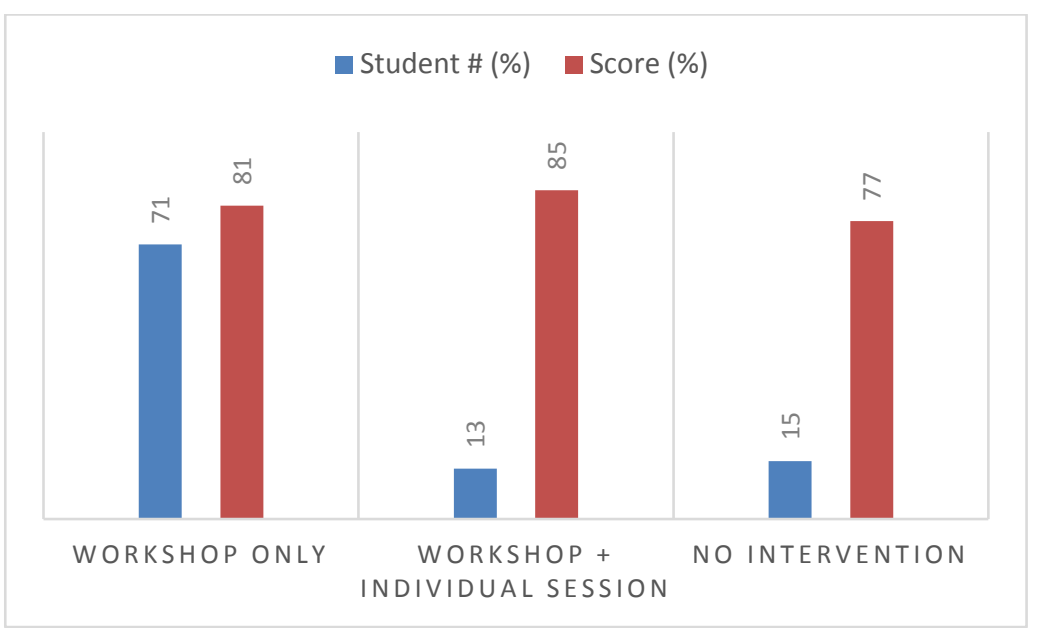

Figure 13: Comparison between intervention attendance and task performance

Only 16 of the 128 students came for individual sessions at the writing centre. Consultant feedback shows that students most frequently (61\%) only required assistance at sentence and paragraph level. Issues at an organisation level were minimal (22\%).

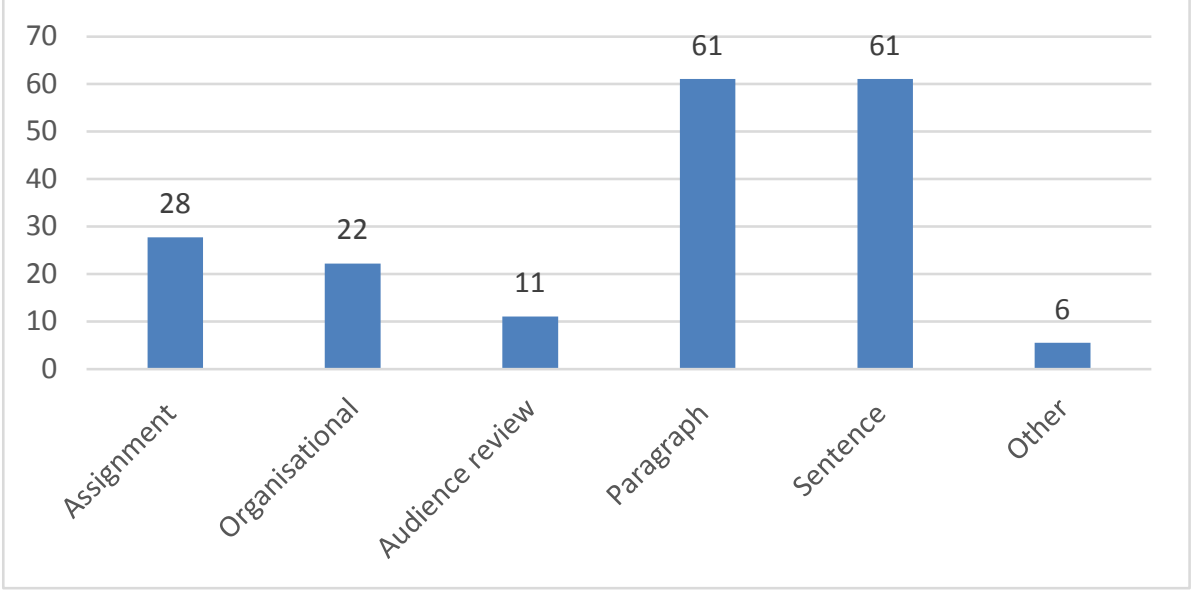

Figure 14: Individual session tutorial frequency

Student performance regarding the critical reflective essay was generally very good. The class average for this particular writing activity was 81 per cent. The students who attended both the workshop and individual sessions obtained an average score of 85 per cent which is 7 per cent higher than the average score of the students who did not attend either of the interventions. The 
same limitations apply to this cohort: the sample sizes of students who did not attend (15\%) and who attended both the workshop and individual session (13\%) are essentially too small to compare. Again, it is unethical to create a control group that would be denied the opportunity to engage with an intervention that could possibly improve their academic performance. Furthermore, it is not certain to what extent the writing interventions impacted students' performance, as there is no pre-intervention sample writing (of the same genre) against which the possible impact can be measured.

\section{CONCLUSION AND RECOMMENDATIONS FOR FUTURE INITIATIVES}

Both student cohorts appear to have perceived the writing interventions positively and they generally performed well in their respective discipline-specific writing tasks. However, it is not clear to what extent the workshops and individual sessions at the writing centre impacted their performance as a result of various mediating factors. The number of students who chose not to participate in the writing interventions is statistically too small in both cohorts to be meaningful. However, for ethical reasons, no control groups could be used to compare student performance. In addition, there are no pre-intervention writing samples of the same genre that could be used to compare students' writing skills. This would require that content lecturers request students to make submissions that do not count for marks, which could affect the number of students who actually complete the task, as well as the quality of their submissions. These additional submissions would also need to be assessed by the content lecturer, thereby adding to academics' current workload and ultimately jeopardising their willingness to collaborate with the writing centre.

Another limitation is that data on students' individual levels of proficiency is not always available, as not all first-year students write the National Benchmark tests (NBTs) and even if they do, these results are not necessarily a good predictor of academic performance (WilsonStrydom 2012). Students with a high English proficiency are likely to perform well on written tasks, regardless of whether they attended additional writing interventions or not. On the other hand, students with a very low proficiency would require numerous writing interventions before an improvement in their writing is evident.

The results of the interventions with the Medical and Law faculties offer some insight into how collaborative partnerships might unfold at universities. Drawing on the UFS writing centre initiatives, it is recommended that a more structured, purposeful writing-intensive approach needs to be undertaken within various disciplines. This would involve conducting a more detailed case study of smaller groups of students within different disciplines in order to 
determine the most effective methodology to address their writing needs. To begin with, a needs analysis of writing tasks required at various levels of study would have to be conducted within the disciplines. Adopting a more writing-intensive approach to teaching and learning across disciplines would furthermore require the incorporation of academic writing tasks into curricula from first-year level onwards, so as provide students with sufficient opportunity to acquire academic writing proficiency. In terms of implementation, either academic staff would need to take responsibility for teaching the conventions of academic writing within their disciplines, or they could collaborate with language practitioners at language centres or writing centres to aid them in addressing students' subject-specific writing needs. Ultimately, a more writingintensive approach is necessary if the institution is to effectively address the access and success of a varied, predominantly academically underprepared student population at the university.

\section{REFERENCES}

Archer, Arlene. 2008. Investigating the effect of writing centre interventions on student writing. South African Journal of Higher Education 22(2): 210-226.

Archer, A. 2010. Challenges and potentials for writing centres in South African tertiary institutions. South African Journal of Higher Education 24(4): 495-510.

Bailey, Kathleen, M. 1996. Voices from the language classroom: Qualitative research in second language education. Cambridge: Cambridge University Press.

Bean, John, C. 2011. Engaging ideas: The professor's guide to integrating writing, critical thinking, and active learning in the classroom. San Francisco: John Wiley \& Sons.

Boughey, Chrissie. 2002. 'Naming' students' problems: An analysis of language-related discourses at a South African university. Teaching in Higher Education 7(3): 295-307.

Britton, James. 1972. Writing to learn and learning to write. DOCUMENT RESUME CS 200 145: 31.

Burke, Penny, J. 2008. Writing, power and voice: Access to and participation in higher education. Changing English 15(2): 199-210.

Clarence, Sherran. 2012. Making inter-disciplinary spaces for talk about and change in student writing and literacy development. Teaching in Higher Education 17(2): 127-137.

Condon, William and Carol Rutz. 2012. A taxonomy of writing across the curriculum programs: Evolving to serve broader agendas. College Composition and Communication 64(2): 357-382.

Dannels, Deanna, P. and Amy, L. Housley Gaffney. 2009. Communication across the curriculum and in the disciplines: A call for scholarly cross-curricular advocacy. Communication Education 58(1): 124-153.

Department of Higher Education and Training. 2014. White Paper on Post-School Education and Training: Building an expanded, effective and integrated post-school system. Pretoria: DHET.

Gee, James, P. 1990. Social linguistics and literacies: ideology in discourses. Basingstoke: Falmer.

Hutchings, Cathy. 2006. Reaching students: lessons from a writing centre. Higher Education Research \& Development 25(3): 247-261.

Lea, Mary, R. and Brian V. Street. 2006. The 'academic literacies' model: Theory and applications. Theory into Practice 45(4): 368-377.

Lillis, Theresa M. 2001. Student writing: Access, regulation, desire. London: Routledge.

Lillis, Theresa and Joan Turner. 2001. Student writing in Higher Education: Contemporary confusion, 
traditional concerns. Teaching in Higher Education 6(1): 57-68.

Pica, Teresa, Richard Young and Catherine Doughty. 1987. The impact of interaction on comprehension. Tesol Quarterly 21(4): 737-758.

Thesen, Lucia and Ermien van Pletzen. 2006. Academic literacy and the languages of change. London: Continuum.

Wilson-Strydom, Merridy. 2012. Using the NBTs to inform institutional understandings of 'underpreparedness': Implications for admissions criteria. South African Journal of Higher Education 26(1): 136-151. 